\title{
Design, modeling and simulation of Fuzzy controlled SVC for 750 km (N/8) Transmission line
}

\author{
Murali. Matcha ${ }^{1}$, Sharath Kumar. Papani ${ }^{1}$, Vijetha. Killamsetti ${ }^{2}$ \\ ${ }^{1}$ Department of Electrical Engineering, N.I.T Warangal, A.P, INDIA-506004 \\ ${ }^{2}$ Department of EEE, GMR Institute of Technology, Srikakulam, A.P, INDIA
}

Email address:

murali233.nitw@gmail.com (Murali. Matcha)

\section{To cite this article:}

Murali. Matcha, Sharath Kumar. Papani, Vijetha. Killamsetti. Design, Modelling and Simulation of Fuzzy Controlled SVC for $750 \mathrm{~km}(\lambda / 8)$ Transmission Line. American Journal of Electrical Power and Energy Systems. Vol. 3, No. 1, 2014, pp. 1-6.

doi: $10.11648 /$ j.epes.20140301.11

\begin{abstract}
Flexible AC transmission system (FACTS) is a technology, which is based on power electronic devices, used to enhance the existing transmission capabilities in order to make the transmission system flexible and independent operation. The FACTS technology is a promising technology to achieve complete deregulation of Power System i.e. Generation, Transmission and Distribution as complete individual units. The loading capability of transmission system can also be enhanced nearer to the thermal limits without affecting the stability. Complete close-loop smooth control of reactive power can be achieved using shunt connected FACTS devices. Static VAR Compensator (SVC) is one of the shunt connected FACTS device, which can be utilized for the purpose of reactive power compensation. Intelligent FACTS devices make them adaptable and hence it is emerging in the present state of art. This paper attempts to design and simulate the Fuzzy logic control of firing angle for SVC in order to achieve better, smooth and adaptive control of reactive power. The design, modeling and simulations are carried out for $\lambda / 8$ Transmission line and the compensation is placed at the receiving end (load end).
\end{abstract}

Keywords: Fuzzy Logic, FACTS, SVC

\section{Introduction}

The reactive power generation and absorption in power system is essential since the reactive power is very precious in keeping the voltage of power system stable. The main elements for generation and absorption of reactive power are transmission line, transformers and alternators. The transmission line distributed parameters throughout the line, on light loads or at no loads become predominant and consequently the line supplies charging VAR (generates reactive power). In order to maintain the terminal voltage at the load bus adequate, reactive reserves are needed. FACTS devices like SVC can supply or absorb the reactive power at receiving end bus or at load end bus in transmission system, which helps in achieving better economy in power transfer.

In this paper Transmission line $(\lambda / 8)$ is simulated using $4 \pi$ line segments by keeping the sending end voltage constant. The receiving end voltage fluctuations were observed for different loads. In order to maintain the receiving end voltage constant, shunt inductor and capacitor is added for different loading conditions. SVC is simulated by means of fixed capacitor and thyristor controlled reactor (FC-TCR) which is placed at the receiving end. The firing angle control circuit is designed and the firing angles are varied for various loading conditions to make the receiving end voltage equal to sending end voltage. Fuzzy logic controller is designed to achieve the firing angles for SVC such that it maintains a flat voltage profile. All the results thus obtained, were verified and were utilized in framing of fuzzy rule base in order to achieve better reactive power compensation for the Transmission line $(\lambda / 8)$. Based on observed results for load voltage variations for different values of load resistance, inductance and capacitance a fuzzy controller is designed which controls the firing angle of SVC in order to automatically maintain the receiving end voltage constant.

\section{Operating Principles and Modeling of SVC}

An elementary single phase thyristor controlled reactor [1] (TCR) shown in Fig.1 consists of a fixed (usually air core) reactor of inductance $\mathrm{L}$ and a two anti parallel SCRs. 
The device brought into conduction by simultaneous application of gate pulses to SCRs of the same polarity. In addition, it will automatically block immediately after the ac current crosses zero, unless the gate signal is reapplied. The current in the reactor can be controlled from maximum (SCR closed) to zero (SCR open) by the method of firing delay angle control. That is, the SCR conduction delayed with respect to the peak of the applied voltage in each half-cycle, and thus the duration of the current conduction interval is controlled. This method of current control is illustrated separately for the positive and negative current cycles in Fig.2 where the applied voltage $\mathrm{V}$ and the reactor current $\mathrm{iL}(\alpha)$ at zero delay angle (switch fully closed) and at an arbitrary $\alpha$ delay angle are shown. When $\alpha=0$, the SCR closes at the crest of the applied voltage and evidently the resulting current in the reactor will be the same as that obtained in steady state with a permanently closed switch. When the gating of the SCR is delayed by an angle $\alpha(0 \leq \alpha$ $\leq \pi / 2$ ) with respect to the crest of the voltage, the current in the reactor can be expressed [1] as follows:

$$
\begin{gathered}
\mathrm{V}(\mathrm{t})=\mathrm{V} \cos \omega \mathrm{t} . \\
\mathrm{i}_{\mathrm{L}}=(1 / \mathrm{L})_{\alpha}{ }^{\omega \mathrm{t}} \mathrm{V}(\mathrm{t}) \mathrm{dt}=(\mathrm{V} / \omega \mathrm{L})(\sin \omega \mathrm{t}-\sin \alpha)
\end{gathered}
$$

Since the SCR, by definition, opens as the current reaches zero, is valid for the interval $\alpha \leq \omega t \leq \pi-\alpha$. For subsequent negative half-cycle intervals, the sign of the terms in (1) becomes opposite.

In (1) the term $(\mathrm{V} / \omega \mathrm{L}) \sin \alpha=0$ is offset which is shifted down for positive and up for negative current half-cycles obtained at $\alpha=0$, as illustrated in Fig.2. Since the SCRs automatically turns off at the instant of current zero crossing of SCR this process actually controls the conduction intervals (or angle) of the SCR. That is, the delay angle $\alpha$ defines the prevailing conduction angle $\sigma(\sigma=\pi-2 \alpha)$. Thus, as the delay angle $\alpha$ increases, the corresponding increasing offset results in the reduction of the conduction angle $\sigma$ of the SCR, and the consequent reduction of the reactor current. At the maximum delay of $\alpha=\pi / 2$, the offset also reaches its maximum of $\mathrm{V} / \omega \mathrm{L}$, at which both the conduction angle and the reactor current becomes zero. The two parameters, delay angle $\alpha$ and conduction angle $\sigma$ are equivalent and therefore TCR can be characterized by either of them; their use is simply a matter of preference. For this reason, expression related to the TCR can be found in the literature both in terms of $\alpha$ and $\sigma$ [1].

It is evident that the magnitude of the current in the reactor varied continuously by delay angle control from maximum $(\alpha=0)$ to zero $(\alpha=\pi / 2)$ shown in Fig.3, where the reactor current $\mathrm{iL}(\alpha)$ together with its fundamental component $\operatorname{iLF}(\alpha)$ are shown at various delay angles $\alpha$ [1]. However, the adjustment of the current in reactor can take place only once in each-half cycle, in the zero to $\pi / 2$ interval [1]. This restriction result in a delay of the attainable current control. The worst-case delay, when changing the current from maximum to zero (or vice versa), is a half-cycle of the applied ac voltage. The amplitude $\operatorname{ILF}(\alpha)$ of the fundamental reactor current $\operatorname{iLF}(\alpha)$ can be expressed as a function of angle $\alpha[1]$.

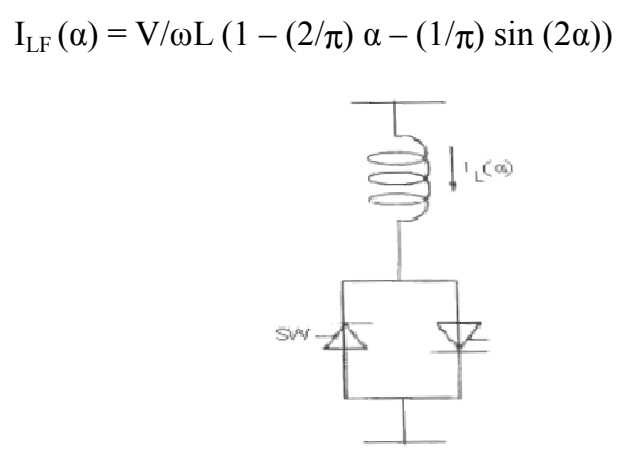

Figure 1. Basic Thyristor Controlled Reactor
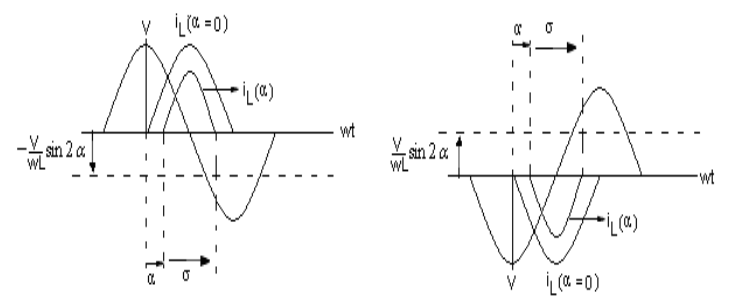

Figure 2. Firing delay angle

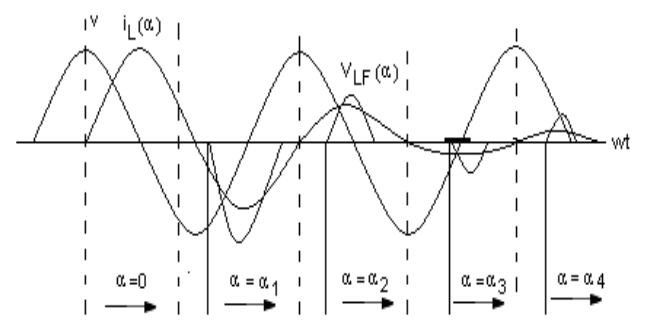

Figure 3. Operating waveforms

Where $\mathrm{V}$ is the amplitude of the applied voltage, $\mathrm{L}$ is the inductance of the thyristor-controlled reactor and $\omega$ is the angular frequency of the applied voltage. The variation of the amplitude ILF $(\alpha)$, normalized to the maximum current ILFmax, $(\mathrm{ILFmax}=\mathrm{V} / \omega \mathrm{L}$ ), is shown plotted against delay angle $\alpha$ shown in Fig.4.

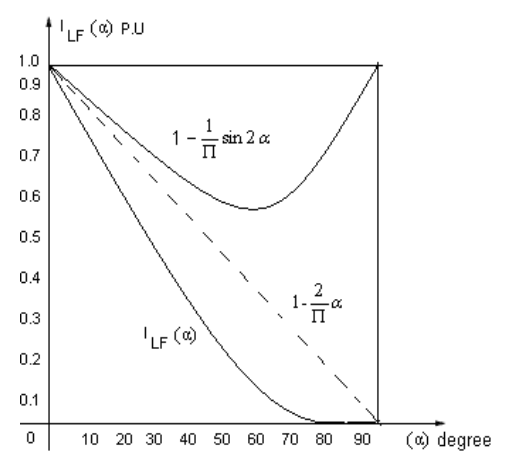

Figure 4. Amplitude variation of the fundamental TCR current with the delay angle $(\alpha)$

It is clear from Fig.4 the TCR can control the fundamental current continuously from zero (SCR open) to a maximum (SCR closed) as if it was a variable reactive admittance. Thus, an effective reactance admittance, $\operatorname{BL}(\alpha)$, 
for the TCR can be defined. This admittance, as a function of angle $\alpha$ is obtained as:

$$
\mathrm{B}_{\mathrm{L}}(\alpha)=1 / \omega \mathrm{L}(1-(2 / \pi) \alpha-(1 / \pi) \sin (2 \alpha))
$$

Evidently, the admittance $\operatorname{BL}(\alpha)$ varies with $\alpha$ in the same manner as the fundamental current $\operatorname{ILF}(\alpha)$. The meaning of (4) is that at each delay angle $\alpha$ an effective admittance $\operatorname{BL}(\alpha)$ can be defined which determines the magnitude of the fundamental current, $\operatorname{ILF}(\alpha)$, in the TCR at a given applied voltage $\mathrm{V}$. In practice, the maximal magnitude of the applied voltage and that of the corresponding current limited by the ratings of the power components (reactor and SCRs) used. Thus, a practical TCR can be operated anywhere in a defined V-I area, the boundaries of which are determined by its maximum attainable admittance, voltage and current ratings as illustrated in the Fig.5a. The TCR limits are established by design from actual operating requirements. If the TCR switching is restricted to a fixed delay angle, usually $\alpha=0$, then it becomes a thyristor switched reactor (TSR). The TSR provide a fixed inductive admittance and thus, when connected to the ac system, the reactive current in it will be proportion to the applied voltage as the V - I plot in the Fig.5b.

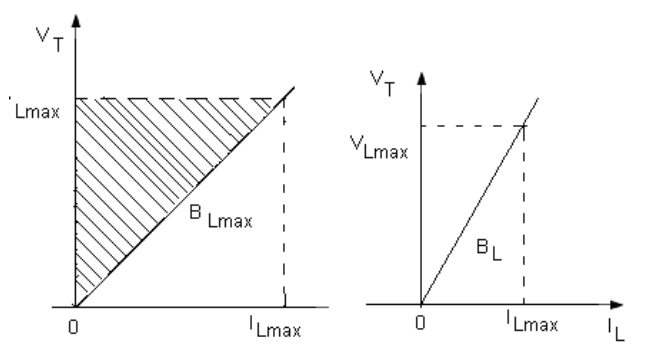

Figure 5. Operating V-I area of (a) For TCR and (b) For TSR

VLmax $=$ voltage limit, ILmax $=$ current limit

BLmax $=$ max admittance of TCR,

$\mathrm{BL}=$ admittance of reactor

A basic VAR generator arrangement using a fixed capacitor with a thyristor-controlled reactor (FC-TCR) shown in Fig. 6 [1].The current in the reactor is varied by the previously discussed method of firing delay angle control. A filter network that has the necessary capacitive impedance at the fundamental frequency to generate the reactive power required usually substitutes the fixed capacitor in practice, fully or partially, but it provides low impedance at selected frequencies to shunt the dominant harmonics produced by the TCR.

The fixed capacitor thyristor-controlled reactor type VAR generator may be considered essentially to consist of a variable reactor (controlled by a delay angle $\alpha$ ) and a fixed capacitor. With an overall VAR demand versus VAR output characteristic as shown in Fig. 7 in constant capacitive VAR generator $(\mathrm{Qc})$ of the fixed capacitor is opposed by the variable VAR absorption (QL) of the thyristor-controlled reactor, to yield the total VAR output $(\mathrm{Q})$ required. At the maximum capacitive VAR output, the thyristor-controlled reactor is off $(\alpha=900)$. To decrease the capacitive output, decreasing delay angle $\alpha$. At zero VAR output increases the current in the reactor, the capacitive and inductive current becomes equal and thus the capacitive and inductive VARs cancel out. With a further decrease of angle $\alpha$, the inductive current becomes larger than the capacitive current, resulting in a net inductive VAR output. At zero delay angle, the thyristor-controlled reactor conducts current over the full 180o interval, resulting in maximum inductive VAR output that is equal to the difference between the VARs generated by the capacitor and those absorbed by the fully conducting reactor.

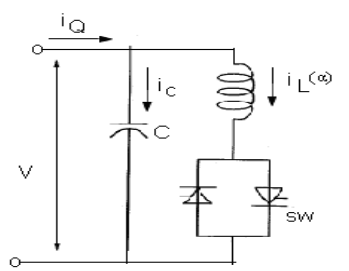

Figure 6. Basic FC-TCR type static generator

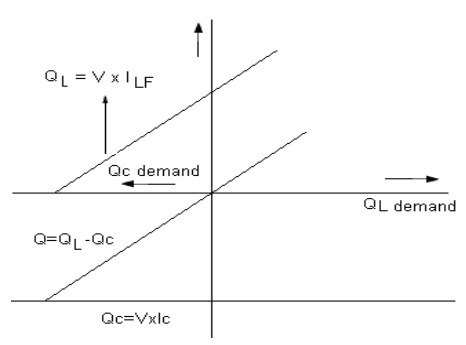

Figure 7. VAR demand versus VAR output characteristic

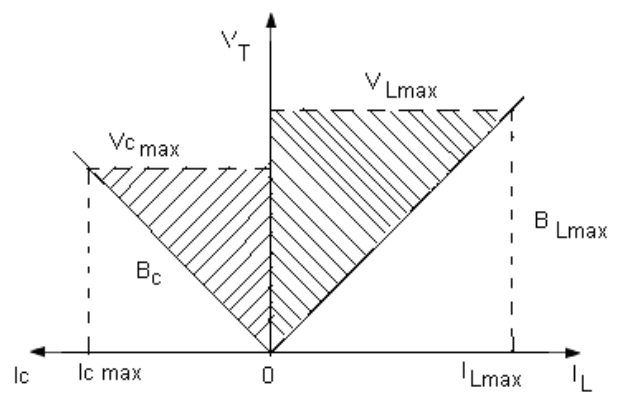

Figure 8. V-I characteristics of the FC-TCR type VAR Generator

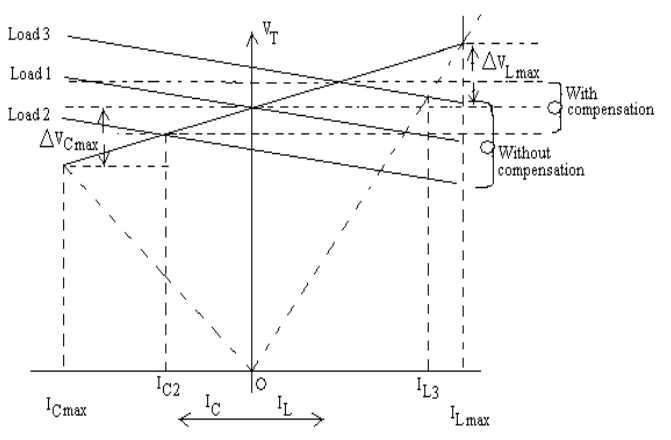

Figure 9. Dynamic V-I Characteristics of SVC with Load lines

In Fig.8 [1] the voltage defines the V-I operating area of the FC-TCR VAR generator and current rating of the major 
power components. In the dynamic V-I Characteristics of SVC along with the Load lines showed in the Fig.9 [1] the load characteristics assumed straight lines for Dynamic studies as easily seen that the voltage improved with compensation when compared without compensation.

$\mathrm{V}_{\mathrm{Cmax}}=$ voltage limit of capacitor

$\mathrm{B}_{\mathrm{C}}=$ admittance of capacitor

$\mathrm{V}_{\text {Lmax }}=$ voltage limit of TCR

$\mathrm{I}_{\mathrm{Cmax}}=$ capacitive current limit

$\mathrm{I}_{\text {Lmax }}=$ inductive current limit

$\mathrm{B}_{\mathrm{Lmax}}=\max$ inductive admittance

\section{Fuzzy Logic Controller}

Fuzzy logic is a new control approach with great potential for real time applications [2] [3]. Fig.10 shows the structure of the fuzzy logic controller (FIS-Fuzzy inference system) in MATLAB Fuzzy logic toolbox. [5][6]. Load voltage and load current taken as input to fuzzy system. For a closed loop control, error input can be selected as current, voltage or impedance, according to control type [7]. To get the linearity triangular membership function is taken with $50 \%$ overlap. The output of fuzzy controller taken as the control signal and the pulse generator provides synchronous firing pulses to thyristors as shown in fig.11. The Fuzzy Logic is a rule based controller, where a set of rules represents a control decision mechanism to correct the effect of certain causes coming from power system [8] [9]. In fuzzy logic, the five linguistic variables expressed by fuzzy sets defined on their respective universes of discourse. Table 1 shows the suggested membership function rules of FC-TCR controller. The rule of this table can be chosen based on practical experience and simulation results observed from the behavior of the system around its stable equilibrium points.

Table 1. Membership Function Rules

\begin{tabular}{ccccccc}
\hline & \multicolumn{5}{c}{ Load } & voltage \\
\hline & & NL & NM & P & PM & PB \\
& NL & PB & PB & NM & NM & NL \\
Load & NM & PB & PB & NM & P & NL \\
& P & P & PM & NM & NM & P \\
& PM & NM & P & NM & NM & PM \\
& PB & NL & NM & NM & NL & NL
\end{tabular}

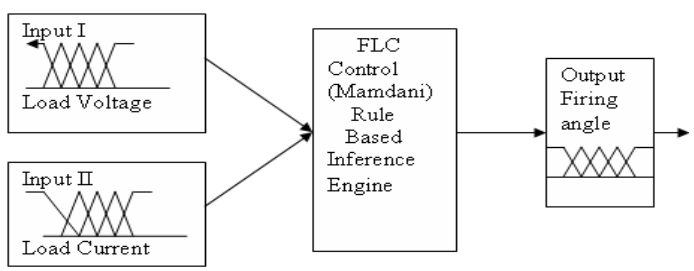

Figure 10. Structure of fuzzy logic controller

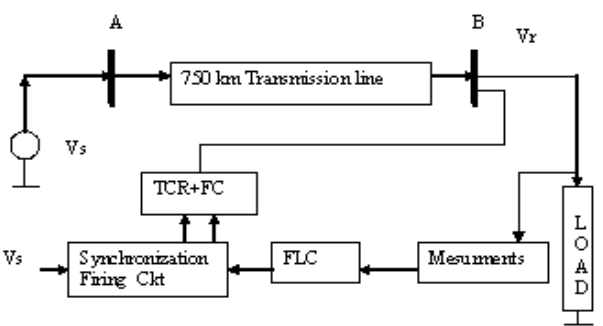

Figure 11. Single Phase equivalent circuit and fuzzy logic control structure of $S V C$

\section{Hardware Implementation}

An available simple two-bus artificial transmission $(\lambda / 8)$ line model of $4 \pi$ line segments with $750 \mathrm{~km}$, distributed parameters were used in this study. The line inductance $0.1 \mathrm{mH} / \mathrm{km}$, capacitance $0.01 \mu \mathrm{f} / \mathrm{km}$ and the line resistance $0.001 \Omega$ were used. Each $\pi$ section is of $187 \mathrm{~km}, 187 \mathrm{~km}$, $188 \mathrm{~km}$ and $188 \mathrm{~km}$. Supply voltage is $230 \mathrm{~V}, 50 \mathrm{~Hz}$ having source internal resistance of $1 \Omega$ connected to node A. Static load is connected at receiving end B .The load resistance was varied to obtain the voltage variations at the receiving end. A shunt branch consisting of inductor and capacitor is added to compensate the reactive power of transmission line. With the change of load and due to Ferranti effect, the variations in voltages are observed at receiving end $\mathrm{B}$ of transmission line [9] [10]. The practical values of shunt elements are varied for different loading conditions to get both sending and receiving end voltages equal. As shown in Table 2.

Table 2. Compensated Practical Values of Inductor and Capacitor

\begin{tabular}{cccc}
\hline S.No & $\begin{array}{c}\text { Load } \\
\text { Resistance }(\boldsymbol{\Omega})\end{array}$ & $\begin{array}{c}\text { Compensating } \\
\text { Inductance }(\mathbf{H})\end{array}$ & $\begin{array}{c}\text { Compensating } \\
\text { Capacitance }(\boldsymbol{\mu} \mathbf{F})\end{array}$ \\
\hline 1 & 500 & 0.8 & 1 \\
2 & 400 & 0.9 & 1 \\
3 & 300 & 0.19 & 2 \\
4 & 200 & 0.18 & 5 \\
5 & 150 & 0.19 & 5 \\
6 & 100 & 0.22 & 8 \\
7 & 50 & 0.14 & 8.5 \\
8 & 40 & 0.14 & 9.0 \\
9 & 30 & 0.14 & 10 \\
10 & 20 & 0.14 & 12 \\
\hline
\end{tabular}

\subsection{Filter Circuit Design}

IC TCA 785 a 16 pin IC shown in Fig. 12 is used in this study for firing the SCRs. This IC having output current of $250 \mathrm{~mA}$ and a fuzzy logic trainer kit with two input variables and having 5 linguistic sets is used. This can generate $5 \mathrm{X} 5$ rules. The output of fuzzy logic which varies from $\mathrm{DC}-10 \mathrm{~V}$ to $+10 \mathrm{~V}$ is given to IC 785 controller pin11, which controls the comparator voltage $\mathrm{VC}$, and the firing angle $\alpha$ for one cycle and $(180+\alpha)$ during negative cycle shown in fig. 13. 


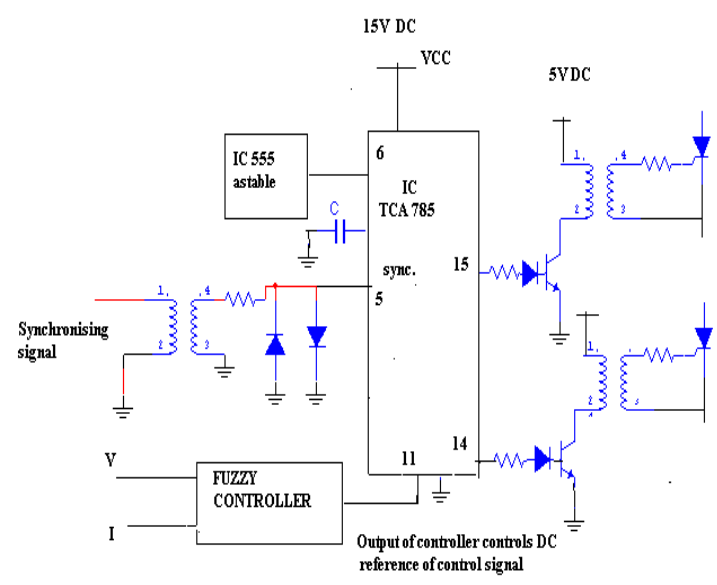

Figure 12. Firing Scheme with TCA 785 IC

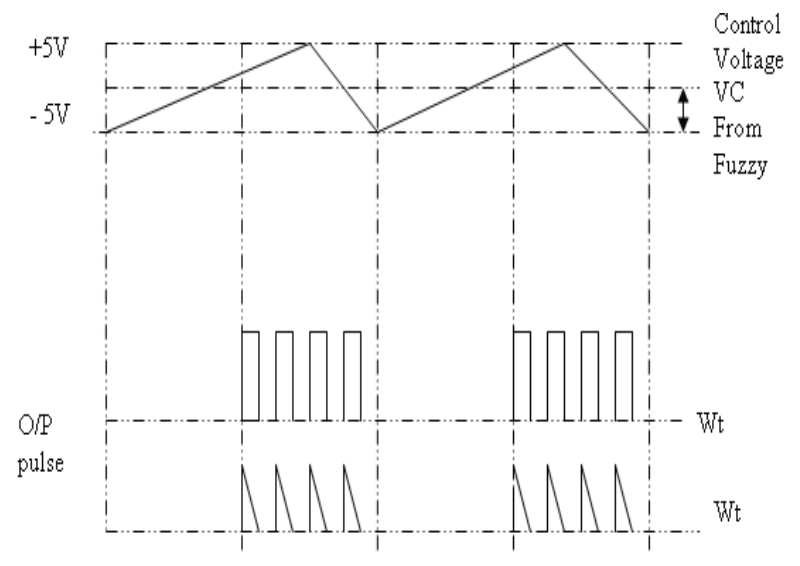

Figure 13. Generation of wave forms of TCA 785 IC

Table 3. Load Voltage Before and After Compensation

\begin{tabular}{|c|c|c|c|c|c|c|}
\hline \multicolumn{2}{|c|}{$\begin{array}{l}\text { Transmission Line Parameters for } \\
\qquad \begin{array}{c}\mathrm{Lt}=10 \mathrm{mh} / \mathrm{km} \\
\mathrm{Ct}=0.1 \mu \mathrm{f} / \mathrm{km} \\
\mathrm{R}=0.001 \Omega\end{array}\end{array}$} & \multicolumn{2}{|c|}{$\begin{array}{l}\text { Before compensation } \\
\text { For Vs=230V (p-p) }\end{array}$} & \multicolumn{3}{|c|}{$\begin{array}{l}\text { After Compensation } \\
\text { For Vs }=230(\mathrm{P}-\mathrm{P})\end{array}$} \\
\hline $\mathbf{R}(\Omega)$ & $V_{S}(r m s)$ Volts & $V_{R}(r m s)$ Volts & $I_{R}$ rms Amp & $V_{R}(r m s)$ Volts & $I_{R}(r m s) A m p$ & $\alpha$ \\
\hline 500 & 162.6 & 270.80 & 0.54 & 162.1 & 2.032 & 90 \\
\hline 400 & 162.6 & 268.10 & 0.67 & 162.4 & 2.036 & 100 \\
\hline 300 & 162.6 & 268.00 & 0.89 & 162. & 2.099 & 102 \\
\hline 200 & 162.6 & 261.10 & 1.30 & 162.7 & 2.182 & 103 \\
\hline 180 & 162.6 & 258.10 & 1.43 & 162.4 & 2.198 & 105 \\
\hline 160 & 162.6 & 256.10 & 1.59 & 162.3 & 2.232 & 106 \\
\hline 140 & 162.6 & 250.30 & 1.78 & 162.8 & 2.299 & 108 \\
\hline 120 & 162.6 & 243.80 & 2.03 & 161.8 & 2.357 & 109 \\
\hline 100 & 162.6 & 234.20 & 2.34 & 162.4 & 2.459 & 112 \\
\hline 80 & 162.6 & 219.50 & 2.74 & 163.3 & 2.651 & 117 \\
\hline 60 & 162.6 & 195.80 & 3.26 & 162.3 & 3.071 & 128 \\
\hline 50 & 162.6 & 156.50 & 3.91 & 162.5 & 4.124 & 158 \\
\hline
\end{tabular}

\section{Test Results}

The transmission line without any compensation was not satisfying the essential condition of maintaining the voltage within the reasonable limits. The effect of increasing load was to reduce the voltage level at the load end. At light loads, the load voltage is greater than the sending end voltage as the reactive power generated is greater than absorbed. At higher loads the load voltage drops, as the reactive power absorbed is greater than generated, as shown in Table 3. Fig.14 and Fig.15 indicates unequal voltage profiles. Fig. 16 clearly shows the firing angle and inductor current control.

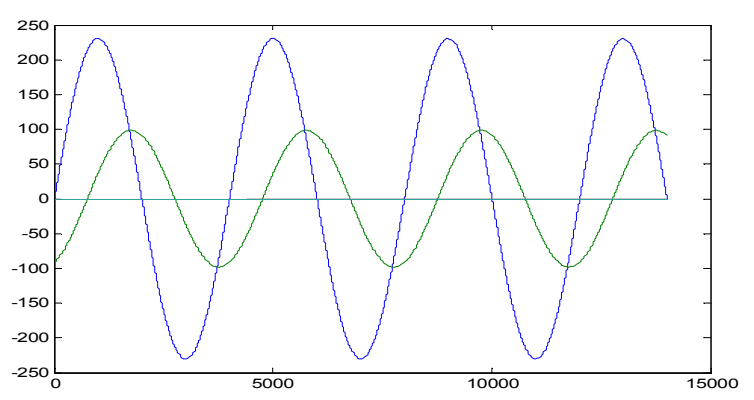

Figure 14. Uncompensated voltages for heavy loads 


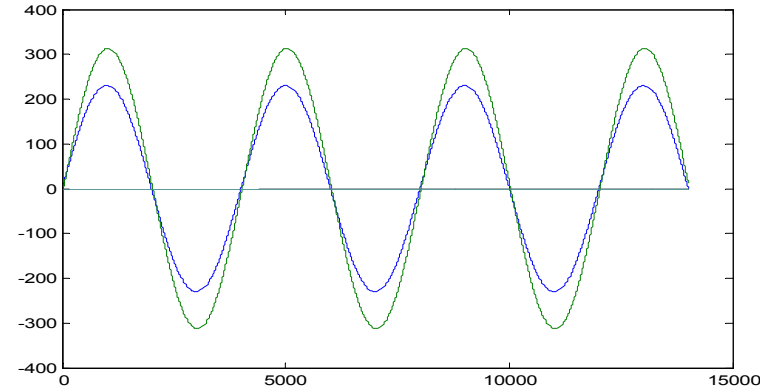

Figure 15. Uncompensated voltage for light load

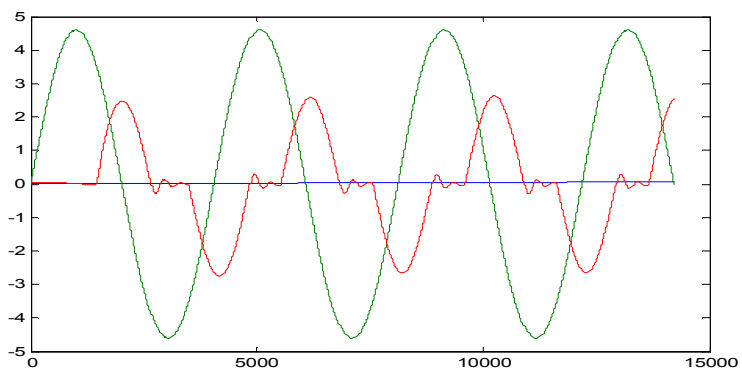

Figure 16. Inductor Current for firing angle $165 \mathrm{deg}$

\section{Conclusions}

This paper presents an "online Fuzzy control scheme for SVC" and it can be concluded that the use of fuzzy controlled SVC (FC-TCR) compensating device with the firing angle control is continuous, effective and it is a simplest way of controlling the reactive power of transmission line. It is observed that SVC device was able to compensate both over and under voltages. Compensating voltages are shown in Fig.17 and Fig.18. The use of fuzzy logic has facilitated the closed loop control of system, by designing a set of rules, which decides the firing angle given to SVC to attain the required voltage. With MATLAB simulations [4], [5] and actual testing it is observed that SVC (FC-TCR) provides an effective reactive power control irrespective of load variations.

\section{Acknowledgements}

The authors would like to thank NIT Warangal for providing required facilities to carry out the simulation of this research work.

\section{References}

[1] Narain. G. Hingorani, "Understanding FACTS, Concepts and Technology Of flexible AC Transmission Systems", by IEEE Press USA.

[2] Bart Kosko, "Neural Networks and Fuzzy Systems A

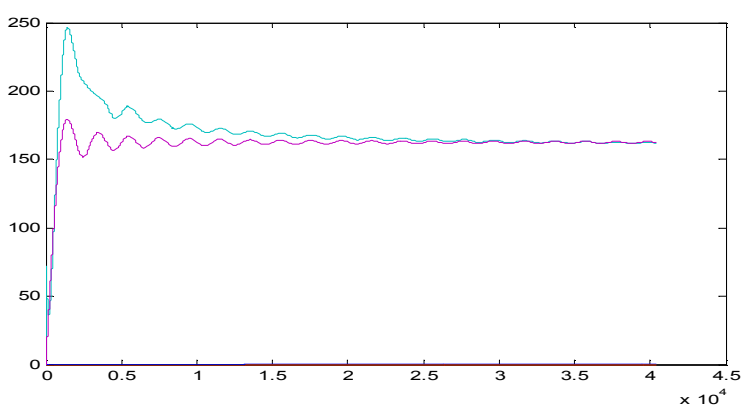

Figure 17. Compensated VR $=V S$ (RMS voltage) for $R=200 \Omega$

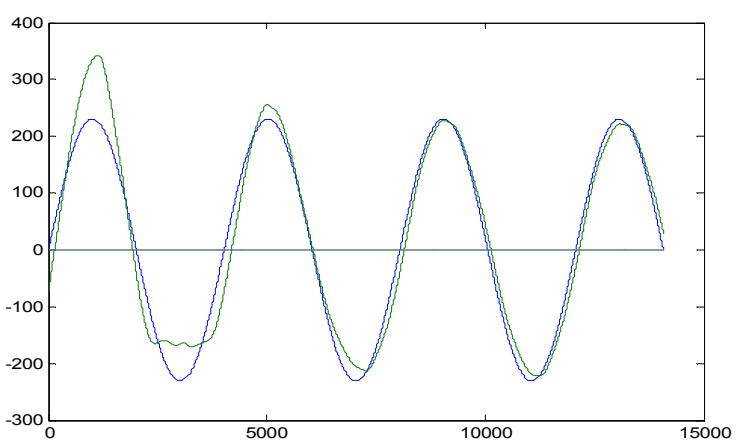

Figure 18. Compensated VR=VS (instantaneous voltage) for $R=200 \Omega$

Dynamical Systems Approach to Machine Intelligence", Prentice-Hall of India New Delhi, June 1994.

[3] Timothy J Ross, "Fuzzy Logic with Engineering Applications", McGraw-Hill, Inc, New York, 1997.

[4] Laboratory Manual for Transmission line and fuzzy Trainer Kit of Electrical Engineering Department, NIT Warangal

[5] SIM Power System User Guide Version 4 MATLAB Manual Periodicals and Conference Proceedings

[6] S.M.Sadeghzadeh, M. Ehsan "Improvement of Transient Stability Limit in Power System Transmission Lines Using Fuzzy Control of FACTS Devices",IEEE Transactions on Power System Vol.13 No.3 ,August 1998

[7] Chuen Chien Lee "Fuzzy Logic in Control Systems: Fuzzy Logic Controller", Part I and Part II. IEEE R. IEEE transactions on system, man, and cybernetics, vol.20 March/April11990

[8] [8] A.M. Kulkarni, "Design of power system stabilizer for single-machine system using robust periodic output feedback controller", IEE Proceedings Part - C, Vol. 150, No. 2, pp. 211 - 216, March 2003. Technical Reports: Papers from Conference Proceedings unpublished)

[9] U.Yolac, T.Talcinoz Dept. of Electronic Eng.Nigde 51200, Turkey "Comparison of Fuzzy Logic and PID Controls For TCSC Using MATLAB"

[10] Jaun Dixon, Luis Moran, Jose Rodrfguz, Ricardo Domke, "Reactive power compensation technology state- of- artreview" (invited paper)

[11] Electrical Engineering Dept Pontifica Universidad Catolica De CHILE. 